\title{
"Taking the pulse" of doctors and nurses to reduce pharmaceutical residues in the water cycle: a ground-breaking survey and its educational implications
}

\author{
M. Adomßent \\ Institute for Environmental and Sustainability Communication, \\ Leuphana University Lüneburg, Germany
}

\begin{abstract}
SAUBER+ is a joint research project with the goal of reducing pollution from healthcare institutions in wastewater. As a partner with expertise in the social sciences, the Institute for Environmental and Sustainability Communication (INFU) of the Leuphana University Lüneburg is investigating risk awareness and the work and behavioral routines of medical and nursing care staff in healthcare institutions. This article describes the conceptual design of the survey, selected findings and their ramifications for designing tailor-made educational measures.

Keywords: pharmaceutical residues, healthcare institutions, risk awareness, physicians, nurses, questionnaire-based survey, professional development.
\end{abstract}

\section{Introduction}

In order to effectively reduce pharmaceutical residues in the wastewater of healthcare institutions, it is important to examine a variety of different approaches and explore their potential for implementation [1]. This ambitious goal cannot be met by simply quantifying wastewater flows and applying technical solutions [2]. On the other hand, it would seem that success depends on involving those that play a role in this problem. This would suggest that educational measures should be initiated to raise the awareness of medical and nursing personnel and change their work and behavioral routines when prescribing or administering pharmaceutical products, as these are important factors in the pollution of healthcare institution wastewater. It will only be possible to develop appropriate communication and 
educational activities when more is known about risk awareness and the prescription and administration routines of pharmaceutical products in these two occupational groups. The results of these activities should be an increase in risk awareness among these groups and their willingness to take action to reduce the entry of pharmaceutical products in the water cycle (e.g. changed behavior regarding prescription or therapy selection, patient education etc.).

This contribution describes each step of this process as they were implemented in the SAUBER+ research project. First of all, it will briefly be presented what physicians and nurses know about contamination by pharmaceutical substances and what they do with this knowledge. Building on these survey results, possible approaches for developing educational activities for both occupational groups are outlined and finally, examples of educational measures will be shown that have been developed and implemented as part of the project.

\section{Surveying medical and nursing personnel}

To date, there have not been any findings in Germany (or in other countries) concerning the risk awareness or behavioral routines of physicians or nurses in healthcare institutions. This gap in the research had to be first closed by conducting a survey so that targeted communication and educational offerings could then be developed for these two occupational groups.

\subsection{Methodological approach}

After preliminary interviews with representatives of the two occupational groups and the management of the participating healthcare institutions, it became clear that a questionnaire-based survey would be the best means for gathering the data needed. In order to minimize the imposition on the respondents, it was decided that the questionnaire response time should not exceed ten minutes. The objective was thus to develop 30-35 items that would cover important survey dimensions of the integrated learning and action model according to Martens and Rost [3], updated by Martens [4], which serves as a theoretical basis for the study. This model served to aid in developing the dependent and independent variables in our research and is thus interesting not only for describing the current state but also and especially for post-evaluation development of methodologies and educational strategies for future educational measures. In the following the selection of the individual items is justified and described in relation to the relevant battery of questions.

- Motivation (8 items): Questions in this category concern responsibility assumption, the perceived seriousness of the problem, as well as vulnerability and susceptibility.

- Intention (4 items): Answers about competence expectancy are important here, especially in relation to future professional development activities. Aspects of effectiveness expectancy are also important (who is considered 
responsible for the problem?), which is closely related to action expectancy and outcome expectancy.

- $\quad$ Routines (4 items): These are not part of the model used in this study but they are nevertheless considered important in their function as antecedent variables. For one thing they reveal alternative explanations of action and, for another, they focus on organizational learning processes in the institutions participating in the project.

- $\quad$ Socio-demography (4 items): Alongside general data about age, gender and education, aspects such as work experience, period of employment as well as training activities are examined.

- $\quad$ Situational barriers (2 items): Institutional factors or rules play a role if they can influence opportunities to take action.

- Actions (6 items): Two action-related dimensions are distinguished here: one is about how pharmaceutical products are handled, and the other is about the relationship participants have to professional development.

- Finally, in consultation with partner institutions also involved in the developing educational and communication measures in the area of risk communication and integration, an item was developed to measure the risk awareness of specific groups of people.

Two versions of the questionnaire were developed, one for the medical staff and one for the nursing care personnel. In order to ensure the comparability of all items, differences between the two versions were kept to a minimum.

\subsubsection{Selection of healthcare institutions}

Institutions were selected for the survey using the criteria of the SAUBER+ project. As a result the focus of the study was less on general hospitals and more on specific healthcare facilities such as elderly care facilities. The participating institutions are briefly described below; information on employee composition can be found in Table 1.

General hospitals

- Hospital 1 is general hospital with a total of 742 beds in 20 specialized departments and 14 medical centers in three locations.

- $\quad$ Hospital 2 provides 348 beds for regular care in 8 specialized departments and a corresponding spectrum of diagnostic services.

- $\quad$ Hospital 3 is a university hospital with 1324 beds in 26 departments.

Nursing care facilities

- Nursing care facility 1 is an institution with about 300 beds for the elderly and people in need of care as well as the mentally handicapped, people with psychiatric disabilities or needing alcohol treatment.

- Nursing care facility 2 is an organization with 19 residential homes and nursing care facilities, 8 of which took part in the survey.

- $\quad$ Nursing care facility 3 does not provide residential services to the elderly. Instead patients are cared for in their own homes and, if needed, family caregivers are given help and advice. 
Table 1: Participating institutions in the survey and employee figures.

\begin{tabular}{|l|c|c|c|c|}
\hline & \multicolumn{2}{|c|}{ Nursing care service } & \multicolumn{2}{c|}{ Medical service } \\
\hline & $\begin{array}{c}\text { Total } \\
\text { employees }\end{array}$ & Participants & $\begin{array}{c}\text { Total } \\
\text { employees }\end{array}$ & Participants \\
\hline Hospital 1 & 967 & 35 & 321 & 29 \\
\hline Hospital 2 & 349 & 28 & 127 & 16 \\
\hline Hospital 3 & 1050 & 12 & 770 & 10 \\
\hline Nursing care facility 1 & 123 & 26 & & \\
\hline Nursing care facility 2 & & & & \\
\hline Location 1 & 46 & 23 & & \\
\hline Location 2 & 44 & 2 & & \\
\hline Location 3 & 57 & 7 & & \\
\hline Location 4 & 33 & 1 & & \\
\hline Location 5 & 46 & 1 & & \\
\hline Location 6 & 29 & 3 & & \\
\hline Location 7 & 29 & 0 & & \\
\hline Location 8 & 41 & 7 & & \\
\hline Nursing care facility 3 & 20 & 6 & & \\
\hline Total & & 151 & & \\
\hline
\end{tabular}

\subsubsection{Characterization of the participants}

A total of 206 individuals took part in the survey from three general hospitals $(\mathrm{GH})$ and ten elderly care facilities (EF). The nursing staff employees, one-third of whom were women and the other two-thirds men, completed a total of 151 questionnaires ( 75 from $\mathrm{GH}, 76$ from $\mathrm{EF}$ ) and made up the majority of responses. Their ages ranged from 22 to 62 years old $(\varnothing=41.4)$ and had worked an average of 16.9 years in their profession since their first professional qualification, with an average of 12 years in their current institution. Almost half $(46.4 \%)$ worked in nursing care, while $12.6 \%$ had the function of head nurse.

Of the medical personnel, a total of 55 individuals worked only in general hospitals. Slightly more than half were men. Their ages ranged from 28 to 65 years old $(\varnothing=43.5)$. Since receiving their license to practice medicine, the respondees worked on average 15.6 years in their profession, with an average period of service of 11 years in their current institution. Of those filling out the questionnaire, $12.7 \%$ had the function of chief physician. Almost one-third worked as senior physicians, $9.1 \%$ as department physicians, $14.5 \%$ as physicians and $16.4 \%$ as assistant physicians.

\section{Results and conclusions regarding educational measures}

In this chapter only selected results directly related to the following sections will be referred to. Detailed descriptions of the results can be found elsewhere [5].

\subsection{Problem perception and susceptibility}

The responses of the two occupational groups differ greatly concerning the assessment of possible effects of pharmaceutical residues on human beings and 
the environment. With a view to their own work environment, only one-fifth of the physicians consider it likely that there would be changes in their official work routines, while slightly more than half of the nurses expected such changes (Figure 1).

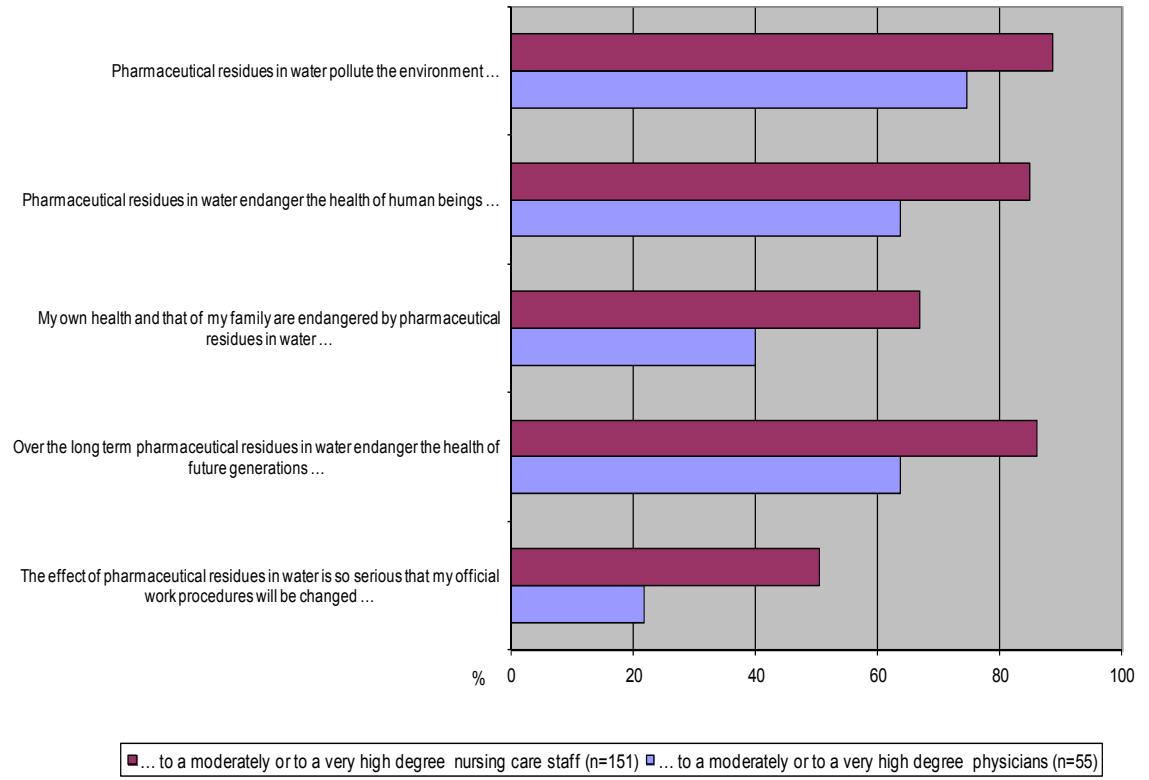

Figure 1: Assessment of impact of pharmaceutical residues on human beings and the environment.

Without exception the respondents of both professional groups assessed their own personal knowledge of the environmental impact of medicine as fairly low (Figure 2). This holds for both the prescription and the administration of pharmaceutical products as well as for the ability to find a balance between patient welfare and environmental impacts. Especially the responses of the physicians to the two items reveal that they lack adequate information, as more than a quarter admit to having no knowledge about the environmental impact of the pharmaceutical products they are prescribing or to being unable to assess how the dosage form or specific treatments affect environmental impact. In contrast, almost $40 \%$ of the nursing care practitioners consider they are well informed regarding the environmental impact of the medicine they are administering, and more than half feel that in their daily work they are consistently able to weigh up possible environmental impacts with the well-being of their patients. An important reason may be that the pressure of daily work routines is so great that, according to the respondees, they do not have the time to seriously consider environmentally friendly alternatives. More than half of the physicians and almost $40 \%$ of the nurses state that they have no or very little time for considering such alternatives. 


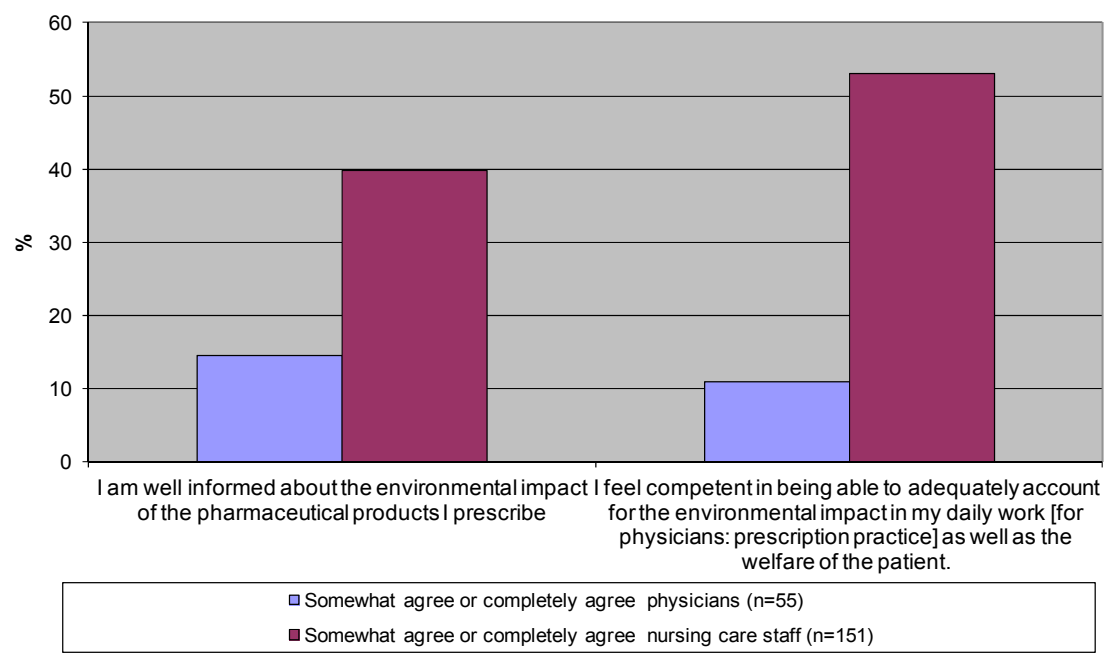

Figure 2: Personal knowledge of the environmental impact of medicine.

Both professional groups think that communication with third parties is very important for reducing the entry of pharmaceutical residues in healthcare institution wastewater, since in both cases almost three-quarters of the respondents consider a promising approach to be discussing this problem with others in order to raise their awareness. However, the question as to awareness-raising by physicians among groups they considered relevant was formulated slightly differently. They were asked who they would speak to on their own initiative. The three most important target groups were (in this order) patients, nurses, and fellow physicians.

\subsection{Environmental impacts in own professional work routines}

Relatively few participants in the study consciously take the environmental impact of pharmaceutical products into account in their professional work. It is also important to note that the nursing care staff, with values between one-sixth and one-fourth per item, is more active than the physicians, more than $5 \%$ of whom only report having already changed their practice in prescribing pharmaceutical products or selecting treatment. The stated willingness to pay greater attention in future to environmental impacts resulting from one's own professional work routines is considerably higher, with agreement rates in both occupational groups reaching 34.5 to $61.8 \%$.

Comparatively few of the respondents say that they have already attended professional development activities with a focus on the relationship of nursing care practice or medical indication and their impact on the environment. While almost $12 \%$ of the nursing care personnel said they had, there was not a single physician that had taken part in such an activity. At the same time, there is a certain level of demand as more than half can imagine attending such professional development activities focused on the environment (Figure 3). 


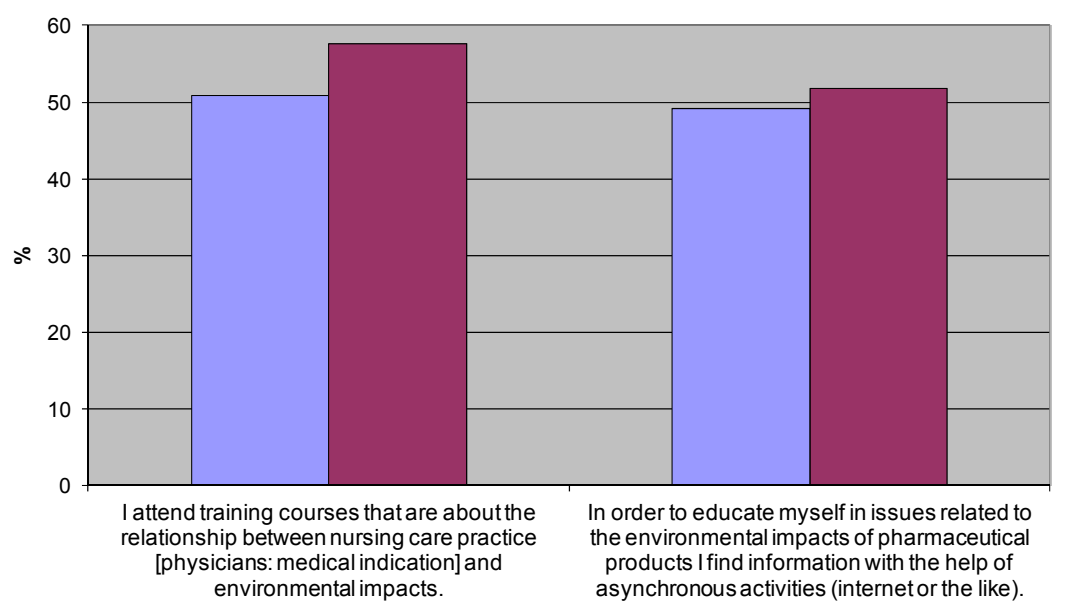

口I could imagine doing that Physiciancs $(n=55) \quad$ al could imagine doing that Nursing care workers $(n=151)$

Figure 3: Responses on professional training in the environmental impact of medicine.

However, the added percentages of those who are moderately uninterested or would even completely rule out taking part, at one quarter $(25.1 \%)$ for the nursing care staff and almost two-fifths $(38.2 \%)$ for physicians, is not negligible. A look at the figures of those who report looking for information in the internet about the environmental impact of pharmaceutical products shows that the percentages of the different response categories are largely similar to the distribution of responses to the question about attending professional development activities. However there is an important difference in that more than one-tenth of the physicians consult online information and - in comparison to traditional professional development activities - a considerably smaller percentage of the physicians $(1.8 \%)$ rule out using the internet as a source of information.

\section{Continuing professional education as a strategic approach}

In sum, for the respondees, according to their own critical self-assessment, there is a need for information and professional development on how to handle pharmaceutical residues in the water cycle as well as an interest in such educational activities [cf. 6]. In light of terminological confusion in this area, it seems called for to distinguish more carefully between further education and continuing professional development. Further education is associated with the goal of attaining a clearly defined qualification that will promote one's own career. Such offerings end with an examination (state examinations in nursing care) as well as a new professional title. On the contrary, the area of continuing professional education is considerably less formal as it is mainly about maintaining or increasing knowledge and skills that have already been acquired during the period of professional qualification or activity. Continuing professional 
education thus does not serve the attainment of new qualifications but instead of ensuring that an individual's knowledge corresponds to the current state in medicine or nursing science.

This means then that the focus should be on the area of continuing professional education, since firstly, professional education activities can be implemented more quickly as there is no time-consuming approval of examination regulations or the like. Secondly, the contents can be more flexibly subdivided into smaller units and then designed to meet the needs of specific target groups. Thirdly, this makes it also easier to acquire potential providers for such professional development activities. However, in Germany there is a considerable difference regarding the obligation to undertake professional development between the two occupational groups. Physicians with their own practice as well as those employed in a hospital are obligated to provide evidence that they have attended Continuing Medical Education (CME) activities for a minimum of $250 \mathrm{CME}$-points within a period of five years as per the law on modernizing the statutory health insurance (GKV) of 2004. For members of the nursing care staff, on the other hand, participation in Continuing Nursing Education (CNE) is voluntary. This difference was taken into account when designing professional development activities for both target groups.

\subsection{Professional development for physicians}

Based on the findings from the SAUBER+ project on reducing contaminated wastewater from healthcare institutions, a CME concept "Antibiotic resistances and pharmaceutical products in the water cycle: Risk characterization and courses of action for physicians" was developed. The concept aims to create greater risk awareness among physicians as well as showing how members of this important target group can contribute to reducing the entry of pharmaceutical substances and pathogens into the aquatic environment by changing their work and behavioral routines.

The first stage of the problem analysis is to define the general situation regarding the entry into the water cycle of pharmaceutical substances from healthcare institutions. This includes a comparison of contamination from hospitals with that of private households. Along with Diclofenac, other substances found around the world include the antiepileptic Carbamazepine, the antiinflammatory drug Ibuprofen and the antibiotic Sulfamethoxazole. It should also be investigated to what extent the potential entry of pharmaceutical substances is related to institutionally specific ingredients (using pharmaceutical profiles, e.g. for departments such as psychiatry, oncology, orthopedics etc.). Improving an individual's contribution to effective risk management involves finding ways to identify possible sources of pollution in hospitals and to then evaluate them with the help of illustrative examples based on material and institutionally specific data. Furthermore, microbiological aspects and especially antibiotic resistance are foregrounded as topics that currently have a very high relevance [7]. First of all, using selected broadband antibiotics often used in hospitals, it is important to show how bacteria become resistant and how as a result of the prescription of antibiotics resistance genes are mobilized and enter bacterial species that then function as 
typical infectious agents in hospitals. It is necessary to understand how bacteria inactivate antibiotics or modify the target site of the antibiotic in their cells so that they lose their effectiveness. It is important to point out that these processes are not caused by a lack of hygiene. Instead, the causal chain of events must be studied through which different resistant bacteria find their way through the municipal wastewater system to the environment. Practical help is given in this section by reference to the widespread establishment of antibiotic stewardship (ABS) working groups and ABS network recommendations for application in a particular context. The final section on risk management and risk communication also represents the core of the module. It clearly explains what different possibilities physicians have to contribute to solving the problem. After all, it is physicians who also play a key role in the communication of this issue by disseminating information to nursing staff and to patients. Examples show how this role of physicians can be strategically exploited.

This concept has been developed so that it can be adapted to specific local circumstances. It was implemented as a pilot program as part of a professional development course for 33 physicians in the Ortenau Clinic in Offenburg on 20 October 2014. In two talks by project members Prof. Jonas on the epidemiology of antibiotic resistances and Prof. Kümmerer on pharmaceutical substances in the water cycle, the main findings of the SAUBER+ project were presented for discussion. These two talks were complemented by a contribution by Dr. Auer, who in his function as head of clinic hygiene in the Ortenau Clinic presented the activities of the in-house ABS working group. Following these presentations, there was a lively discussion between the speakers and the audience, which in addition to members of the clinic included many physicians with a private practice in the region. The most important issue for the physicians was what they would have to change in their own work and behavioral routines in order to make a personal contribution to reducing the danger of these substances reaching the environment. Participation in the program - which all of participants had said was very interesting and which had been reported on in the regional press - was approved by the Baden-Württemburg Medical Association as a professional development course with three CME points.

\subsection{Professional development for members of the nursing staff}

Under the conditions that there should be a similar concept for both medical and nursing personnel and that the nursing staff are not legally required to undertake professional development, it was important to reach as many individuals in the target group as possible. After extensive research it was decided that a multimedia professional development program from the Thieme publishing house in cooperation with the German Nursing Council would be a suitable platform. The educational journal associated with this platform is CNE.fortbildung together with CNE.magazin. A survey article with the title "Dangerous residues in clinic wastewater?" was produced for nursing service personnel with contributions from many project members and was launched in the journal CNE.magazin [8]. This publication is used by 460 clinics to maintain the qualifications of their employees 
in the field of health and nursing care up to and including the management level and has a circulation of 81,153 readers (publisher's statistics from 30.04.2015).

\subsection{Institutions, certification and portals - the provider side}

The development of criteria for the approval of professional development activities is regulated by the medical profession. In Germany the legal obligation for physicians to undertake CME is only fulfilled by those activities that have been accredited by a medical association or other healing profession associations and provided with a number of points. Internet-based portals provide access to the greater part of continuing professional development activities both for physicians as well as for nurses. For nursing personnel, the German Nurses' Association operates an important source of information: PflegeWiki (www.pflegewiki.de). Inspired by Wikipedia this knowledge platform for nursing healthcare contains approximately 7,000 articles, including those dealing with education and CNE. In the past there has been repeated criticism that most portals for physicians are run by pharmaceutical companies. The fact that these continuing professional development activities are contrary to the regulations formulated in the Social Insurance Code has led the Federal Cartel Office to warn the state medical associations responsible for the certification of professional development activities and if necessary prohibit authorization of such professional development portals [9].

The fact that, on the one hand, survey participants in the medical and nursing professions have articulated a need for continuing professional education and, on the other, there is a lack of professional development activities on issues related to the entry of pharmaceutical residues in the water cycle - not even by the German Medical Association - is shown in a survey of medical associations on state and federal level. The key function of medical associations in approving and certifying professional development activities for medical personnel makes their response an important indicator for the implementation of such educational activities, or lack thereof. The findings, however, are sobering. Only three state medical associations provide such activities (Mecklenburg-West Pomerania, North Rhine-Westphalia and Baden-Württemberg) and the interest of these could be described as somewhat modest (except for the state medical associations mentioned above only Bavaria and Saxony expressed a willingness to cooperate). This defensive behavior is most likely also a reason for the negative responses given to enquiries about developing learning modules at publishing houses and providers of online learning modules that work together with medical associations to offer online professional development activities.

\section{Discussion and outlook}

There is a difficulty in conducting field research as physicians and medical institutions are often unwilling to work together with social scientists as equal partners. It is thus necessary to have collaborators in the medical field before such cooperative projects can be initiated. The fact that the CME event conducted in 
close cooperation with the Ortenau Clinic was certified by the BadenWürttemberg Medical Association without difficulties speaks volumes in comparison to the many unsuccessful attempts by researchers working alone to develop such activities to the stage where they could be offered as a professional development activity.

This aspect of egalitarian communication can be found in an interesting approach to professional development in medical practice. Not least because of the alarming situation that the pharmaceutical industry is a major source of information for physicians, as described above, efforts are being made in other countries to find less problematic alternatives. Canada, for example, has had good experiences with academic detailing (also known as university-based education detailing, educational outreach or public interest detailing [10]), by which is meant the university-based education of physicians in their practices. In a number of studies, a service by medical associations and public institutions was tested to create a convenient way for physicians to educate themselves about current issues or new findings in medical practice. In evaluations of studies published to date on the effects of such approaches, participants were especially appreciative of evidence-based advice and thus of the greater reliability of the information in comparison to the services provided by representatives of pharmaceutical companies [cf. 11].

In addition to the findings discussed above, the survey also draws attention to other important aspects of education and communication. The influence of the hospital as institution should be kept in mind as these organizations have medical, economic and legal functions that must be simultaneously managed [cf. 12]. In this connection the hierarchical difference between medical and nursing personnel is in particular a major obstacle to the joint education of physicians and nurses (co-education), which has an impact not only on patient well-being but also on the harmonization of the prescription and administration practices of both groups to reduce environmental contamination by pharmaceutical substances.

Such an understanding, which could be called professionalism, must ultimately raise awareness for and a capacity to take action to reduce the entry of pharmaceutical residues in the water cycle. This includes the necessity of continuing professional education as well as the willingness to question one's own work routines. In this respect, the survey has revealed what starting points there might be for education providers to the extent that the connection between pharmaceutical residues with issues of antibiotic resistances (ABR) in wastewater should be seen as having a key strategic value as a "door opener" for addressing issues of the contamination of healthcare institution wastewater by pharmaceutical residues within the context of the professional development of physicians and nurses.

\section{Acknowledgement}

The author and the SAUBER+ research partnership would like to thank the German Federal Ministry for Education and Research for its financial support (funding code: 02WRS1280A-J). 


\section{References}

[1] Kümmerer, K. (ed.), Pharmaceuticals in the environment: sources, fate, effects and risks, 3rd ed., Berlin, Springer, 2008.

[2] Kümmerer, K. \& Hempel, M. (eds.), Green and Sustainable Pharmacy, Berlin: Springer, 2013.

[3] Martens, T. \& Rost, J., Der Zusammenhang von wahrgenommener Bedrohung durch Umweltgefahren und der Ausbildung von Handlungsintentionen. Zeitschrift für Experimentelle Psychologie, 45(4), pp. 345-364, 1998.

[4] Martens, T., Was ist aus dem Integrierten Handlungsmodell geworden? Item-Response-Modelle in der sozialwissenschaftlichen Forschung, ed. Kempf, W. \& Langeheine, R., Regener: Berlin, pp. 210-229, 2012.

[5] Adomßent, M., Rode, H., Grunenberg, H. \& Burandt, S., Was Ärzte und Pflegedienstmitarbeiter über Arzneimittelrückstände im Wasserkreislauf wissen und wie sie damit umgehen. Ergebnisse einer Befragung von Beschäftigten aus Einrichtungen des Gesundheitswesens. Korrespondenz Abwasser Abfall, 62 (1), pp. 40-44, 2015.

[6] Emschergenossenschaft (ed.), Pharmaceutical residues in the aquatic system - a challenge for the future. EU cooperation project PILLS, Essen, 2010.

[7] Dryden, M.S., Cooke, J. \& Davey, P., Antibiotic stewardship - more education and regulation not more availability? Journal of Antimicrobial chemotherapy, 64, pp. 885-888, 2009.

[8] Schwencke, S., Gefährliche Rückstände im Klinikabwasser? CNE.Magazin, 5/2014, pp. 22-23, 2014.

[9] Künstner, K.M., Kartellrechtliche Überprüfung der Fortbildungssysteme von Berufskammern. ZWeR-Zeitschrift für Wettbewerbsrecht, 2/2014, 2014.

[10] Albert, D.A.; Anluwalia, K.P.; Ward, A. \& Sadowsky, D., The use of 'academic detailing' to promote tobacco-use cessation counseling in dental offices. JADA, 135, pp. 1700-1706, 2004.

[11] Allen, M., Ferrier, S., O’Connor, N. \& Fleming, I., Family physicians' perceptions of academic detailing: a quantitative and qualitative study. $B M C$ Medical Education, 7 (36), doi: 10.1186/1472-6920-7-36, 2007.

[12] Vogd, W., Decision-Making by Hospital Physicians Complex Cases in the Field of Tension Between Patients' Interests and Administrative and Organizational Constraints, Zeitschrift für Soziologie, 33 (1), pp. 26-47, 2004. 